pure. Splicing reactions were for $1-2 \mathrm{~h}$ at $30^{\circ} \mathrm{C}$. Extracted and precipitated RNAs were fractionated on a denaturing $8 \%$ polyacrylamide gel; the gel and electrophoresis buffer $(1 \times \mathrm{TBE})$ contained $10 \mathrm{mM}$ dithiothreitol (DTT) and gels were pre-run for at least $6 \mathrm{~h}$.

Splice-site mapping. For 5' -splice-site mapping, we included the Ad5-1S premRNA in splicing reactions as described and gel-purified the $5^{\prime}$ exon intermediate. To generate a standard, the Ad5-1S/30 fragment was treated with $\mathrm{AgNO}_{3}$ (ref. 15), and the 10-nucleotide labelled product of silver cleavage ( $5^{\prime}$-pCAGCUGUUGC $(\mathrm{dU})_{\mathrm{SH}^{-}} 3^{\prime}$ ) was purified in a $20 \%$ polyacrylamide denaturing gel containing $10 \mathrm{mM}$ DTT. Following elution, we desalted the oligonucleotide in a Sep-Pac $\mathrm{C}_{18}$ cartridge (Waters) and dried it in vacuo. The purified 5' exon intermediate, the $\mathrm{Ag}^{+}$-cleaved fragment, and the Ad5-1 premRNA were digested with RNase $\mathrm{T}_{1}$ and fractionated in a $20 \%$ polyacrylamide denaturing gel containing $10 \mathrm{mM}$ DTT. RNase $\mathrm{T}_{1}$ digestions ${ }^{9}$ contained $10 \mathrm{mM}$ DTT.

For 3 '-splice-site mapping, extracted and precipitated RNAs from $100-\mu \mathrm{l}$ splicing reactions (Fig. 3b, lanes 15 and 16) were reverse transcribed using a DNA primer (Ad.33) complementary to the 3 '-terminal 21 nucleotides of the Ad3-1S substrate. We used the products of these reactions as PCR templates, with Ad.33 primer and another oligonucleotide (Ad.55) corresponding to the 5 '-terminal 20 nucleotides of the Ad3-1S substrate, and sequenced the PCR products derived from ligated exons.

Received 25 February; accepted 21 May 1997

1. Krämer, A. in Pre-mRNA Processing (ed. Lamond, A.) 35-64 (Landes, Austin, 1995).

2. Steitz, T. A. \& Steitz, J. A. A general two-metal-ion mechanism for catalytic RNA. Proc. Natl Acad. Sci. USA 90, 6498-6502 (1993).

3. Piccirilli, J. A., Vyle, J. S., Caruthers, M. H. \& Cech, T. R. Metal ion catalysis in the Tetrahymena ribozyme reaction. Nature 361, 85-88 (1993).

4. Cosstick, R. \& Vyle, J. S. Synthesis and properties of dithymidine phosphate analogues containing 3'thiothymidine. Nucleic Acids Res. 18, 829-835 (1990).

5. Jaffe, E. K. \& Cohn, M. Divalent cation-dependent stereospecificity of adenosine $5^{\prime}-O$-(2-thiotriphosphate) in the hexokinase and pyruvate kinase reactions: The absolute stereochemistry of the diastereomers of adenosine 5'-O-(2-thiotriphosphate). J. Biol. Chem. 253, 4823-4825 (1978).

6. Jaffe, E. K. \& Cohn, M. Diastereomers of the nucleoside phosphorothioates as probes of the structure of the metal nucleotide substrates and of the nucleotide binding site of yeast hexokinase. J. Biol. Chem. 254, 10839-10845 (1979)

7. Pecoraro, V. L., Hermes, J. D. \& Cleland, W. W. Stability constants of $\mathrm{Mg}^{2+}$ and $\mathrm{Cd}^{2+}$ complexes of adenine nucleotides and thionucleotides and rate constants for formation and dissociation of MgATP and MgADP. Biochemistry 23, 5262-5271 (1984).

8. Sigel, R. K. O., Song, B. \& Sigel, H. Stabilities and structures of metal ion complexes of adenosine $5^{\prime}-O-$ thiomonophosphate $\left(\mathrm{AMPS}^{2-}\right)$ in comparison with those of its parent nucleotide $\left(\mathrm{AMP}^{2-}\right)$ in aqueous solution. J. Am. Chem. Soc. 119, 744-755 (1997).

9. Moore, M. J. \& Sharp, P. A. Site-specific modification of pre-mRNA: The 2'-hydroxyl groups at the splice sites. Science 256, 992-997 (1992).

10. Solnick, D. Trans splicing of mRNA precursors. Cell 42, 157-164 (1985).

11. Pearson, R. G. Acids and bases. Science 151, 172-177 (1966).

12. Dantzmann, C. L. \& Kiessling, L. L. Reactivity of a $2^{\prime}$-thio nucleotide analog. J. Am. Chem. Soc. 118, $11715-11719$ (1996).

13. Burgin, A. B., Huizenga, B. N. \& Nash, H. A. A novel suicide substrate for DNA topoisomerases and site-specific recombinases. Nucleic Acids Res. 23, 2973-2979 (1995).

14. Seiwert, S. D. \& Steitz, J. A. Uncoupling two functions of the U1 small nuclear ribonucleoprotein particle during in vitro splicing. Mol. Cell. Biol. 13, 3135-3145 (1993).

15. Vyle, J. S., Connolly, B. A., Kemp, D. \& Cosstick, R. Sequence- and strand-specific cleavage in oligodeoxyribonucleotides and DNA containing 3'-thiothymidine. Biochemsitry 31, 3012-3018 (1992).

16. Weinstein, L. B., Earnshaw, D. J., Cosstick, R. \& Cech, T. R. Synthesis and characterization of an RNA dinucleotide containing a 3'-S-phosphorothiolate linkage. J. Am. Chem. Soc. 118, 10341-10350 (1996).

17. Konarska, M. M. \& Sharp, P. A. Electrophoretic separation of complexes involved in the splicing of precursors to mRNAs. Cell 46, 845-855 (1986).

18. Reyes, J. L., Kois, P., Konforti, B. B. \& Konarska, M. M. The canonical GU dinucleotide at the 5 ' splice site is recognized by p220 of the U5 snRNP within the spliceosome. RNA 2, 213-225 (1996).

19. Narlikar, G. J., Gopalakrishnan, V., McConnell, T. S., Usman, N. \& Herschlag, D. Use of binding energy by an RNA enzyme for catalysis by positioning and substrate destabilization. Proc. Natl Acad. Sci. USA 92, 3668-3672 (1995)

20. Aebi, M., Hornig, H., Padgett, R. A., Reiser, J. \& Weissmann, C. Sequence requirements for splicing of higher eukaryotic nuclear pre-mRNA. Cell 47, 555-565 (1986).

21. Tarn, W.-Y. Site-specific substitution of inosine at the terminal positions of a pre-mRNA intron Implications for the configuration of the terminal base interaction. Biochimie (in the press).

22. Anderegg, G. in Comprehensive Coordination Chemistry: The Synthesis, Reactions, Properties and Applications of Coordination Compounds (eds Wilkinson, G., Gillard, R. D. \& McCleverty, J. A.) 777792 (Pergamon, Oxford, 1987)

23. Freemont, P. S., Friedman, J. M., Beese, L. S., Sanderson, M. R. \& Steitz, T. A. Cocrystal structure of an editing complex of Klenow fragment with DNA. Proc. Natl Acad. Sci. USA 85, 8924-8928 (1988).

24. Moore, M. J. \& Sharp, P. A. Evidence for two active sites in the spliceosome provided by stereochemistry of pre-mRNA splicing. Nature 365, 364-368 (1993).

25. Sontheimer, E. J. \& Steitz, J. A. The U5 and U6 small nuclear RNAs as active site components of the spliceosome. Science 262, 1989-1996 (1993).

26. Query, C. C., Moore, M. J. \& Sharp, P. A. Branch nucleophile selection in pre-mRNA splicing: evidence for the bulged duplex model. Genes Dev. 8, 587-597 (1994).

27. Dignam, J. D., Lebovitz, R. M. \& Roeder, R. G. Accurate transcription initiation by RNA polymerase II in a soluble extract from isolated mammalian nuclei. Nucleic Acids Res. 11, 1475-1489 (1983).
28. Abmayr, S. M., Reed, R. \& Maniatis, T. Identification of a functional mammalian spliceosome containing unspliced pre-mRNA. Proc. Natl Acad. Sci. USA 85, 7216-7220 (1988).

Acknowledgements. We thank M. Hamm and L. Munishkina for oligonucleotide synthesis, W.-Y. Tarn for communicating unpublished results, members of our laboratory for advice and discussions, and J. Curley, M. Hamm and A. Yoshida for comments on the manuscript. E.J.S. was supported in part by a postdoctoral fellowship from the Jane Coffin Childs Memorial Fund for Medical Research. E.J.S. and S.S. are research associates and J.A.P. is an assistant investigator of the Howard Hughes Medical Institute.

Correspondence and requests for materials should be addressed to J.A.P. (e-mail: jpicciri@midway. uchicago.edu).

\section{A second catalytic metal ion in a group I ribozyme}

\section{Lara B. Weinstein*, B. C. N. M. Jones $\dagger$, Richard Cosstick $\dagger$ \& Thomas R. Cech*}

${ }^{*}$ Howard Hughes Medical Institute, Department of Chemistry and Biochemistry, University of Colorado, Boulder, Colorado 80309-0215, USA

$\dagger$ Robert Robinson Laboratory, Department of Chemistry, University of Liverpool, Liverpool L69 3BX, UK

Although only a subset of protein enzymes depend on the presence of a metal ion for their catalytic function, all naturally occurring RNA enzymes require metal ions to stabilize their structure and for catalytic competence ${ }^{1}$. In the self-splicing group I intron from Tetrahymena thermophila ${ }^{2}$, several divalent metals can serve structural roles, but only $\mathrm{Mg}^{2+}$ and $\mathrm{Mn}^{2+}$ promote splice-site cleavage and exon ligation ${ }^{3,4}$. A study of a ribozyme reaction analogous to $5^{\prime}$-splice-site cleavage by guanosine uncovered the first metal ion with a definitive role in catalysis. Substitution of the $3^{\prime}$-oxygen of the leaving group with sulphur resulted in a metal-specificity switch, indicating an interaction between the leaving group and the metal ion ${ }^{5}$. Here we use $3^{\prime}$ (thioinosylyl)-( $\left.3^{\prime} \rightarrow 5^{\prime}\right)$-uridine $e^{6}$, IspU, as a substrate in a reaction that emulates exon ligation. Activity requires the addition of a thiophilic metal ion $\left(\mathrm{Cd}^{2+}\right.$ or $\left.\mathrm{Mn}^{2+}\right)$, providing evidence for stabilization of the leaving group by a metal ion in that step of splicing. Based on the principle of microscopic reversibility, this metal ion activates the nucleophilic $3^{\prime}$-hydroxyl of guanosine in the first step of splicing, supporting the model of a two-metal-ion active site ${ }^{7}$.

The self-splicing reaction performed by the Tetrahymena intron consists of two consecutive phosphotransesterification reactions. The mechanism of the first step, $5^{\prime}$-splice-site cleavage, has been studied using a truncated form of the intron (L-21 ScaI) in the forward reaction $(\mathrm{G}+\mathrm{CCCUCUpA} \rightarrow \mathrm{GpA}+\mathrm{CCCUCU}$, where only the reactive phosphate is shown explicitly) (Fig. 1a) ${ }^{2,8}$. The second step of splicing, exon ligation, is chemically the reverse of the first step ${ }^{9}$ and is thought to occur in the same active site ${ }^{10,11}$. This step is mimicked by the reverse of the ribozyme reaction $(\mathrm{GpN}+\mathrm{CCCUCU} \rightarrow \mathrm{G}+\mathrm{CCCUCUpN}$, where $\mathrm{N}$ is $\mathrm{A}, \mathrm{C}$ or $\mathrm{U})$ (Fig. 1a $)^{12-14}$. Kinetic studies of this reverse reaction have used dinucleotides with guanosine at the $5^{\prime}$-position. However, inosine will substitute for guanosine in both splicing and the enzymatic forward reaction ${ }^{15,16}$. For ease in chemical synthesis, we chose IspU, an inosine-containing dinucleotide with a $3^{\prime}$-S-phosphorothiolate linkage ${ }^{6}$, to prospect for a metal ion interacting with the leaving group in the reverse reaction (Fig. 1b).

Under conditions previously shown to support the reverse reaction efficiently, namely $\mathrm{pH} 7.0$ and high $\mathrm{MgCl}_{2}$ concentration $(110 \mathrm{mM})^{13}$, only the unmodified dinucleotide, IpU, was a substrate for transesterification (Fig. 2). Addition of $\mathrm{Mn}^{2+}$ (1-100 mM) resulted in progressively higher rates of transesterification of IspU (Fig. 2). To find conditions under which the observed rate constant $\left(k_{\mathrm{obs}}\right)$ reflects the chemical step, a $\mathrm{pH}$ profile was determined for the 
reaction with $\mathrm{IpU}$ (data not shown). From pH 5.5 to $7.0, \log k_{\mathrm{obs}}$ increased linearly with $\mathrm{pH}$, and slopes of 0.91 and 0.79 were measured for reactions in $20 \mathrm{mM} \mathrm{MgCl} 2$ and in $10 \mathrm{mM} \mathrm{MgCl}_{2} /$ $10 \mathrm{mM} \mathrm{MnCl}_{2}$, respectively. This dependence is a hallmark for the actual cleavage event being rate-determining ${ }^{13,17}$. Consequently, all subsequent reactions were done at $\mathrm{pH}$ 5.9. The dinucleotide binds so weakly that it is subsaturating at all accessible concentrations (data not shown). Thus, the observed rates are proportional to the kinetic parameter $k_{\text {cat }} / K_{\mathrm{m}}$, and any difference in binding between the dinucleotides would be manifested in these measurements.

To sample a range of Lewis acids, the reaction was conducted with $\mathrm{Mn}^{2+}, \mathrm{Zn}^{2+}, \mathrm{Cd}^{2+}$ or $\mathrm{Co}^{2+}$ in combination with enough $\mathrm{MgCl}_{2}$ to ensure proper folding of the ribozyme. Although high metal-ion concentration did enhance the rate of reaction, the rate constants were determined with less metal to alleviate nonspecific degradation of the RNA and to accommodate solubility limitations of the metal salts tested. As shown in Fig. 3a, IpU transesterification was catalysed by $\mathrm{Mg}^{2+}$ alone, and substitution of a portion of the $\mathrm{Mg}^{2+}$ with either $\mathrm{Mn}^{2+}$ or $\mathrm{Zn}^{2+}$ stimulated the observed reaction rate, as seen previously in measurements of the forward reaction ${ }^{5}$. In contrast, IspU was not a substrate when only $\mathrm{Mg}^{2+}$ was included in the reaction (Fig. 3b). Addition of $\mathrm{Mn}^{2+}, \mathrm{Cd}^{2+}$ or $\mathrm{Zn}^{2+}$ restored the reaction to rates equivalent to or exceeding that for IpU with $\mathrm{Mg}^{2+}$ alone. Although both $\mathrm{Mn}^{2+}$ and $\mathrm{Cd}^{2+}$ facilitated the IspU reaction more than the IpU reaction (Fig. 3), only $\mathrm{Cd}^{2+}$ gave a true specificity switch: that is, $\mathrm{Mg}^{2+}$ and $\mathrm{Cd}^{2+}$ afforded equivalent rates of reaction with IpU, whereas the $\mathrm{Cd}^{2+}$ rate greatly exceeded that for $\mathrm{Mg}^{2+}$ in the IspU reactions. Considering the preference of $\mathrm{Cd}^{2+}$ for sulphur ligands over oxygen ligands ${ }^{18}$, the metal-specificity switch observed upon changing a single atom in the substrate $\left(3^{\prime}-O \rightarrow 3^{\prime}-S\right)$ supports the conclusion that there is a direct interaction of the metal ion with this atom.

The concentration dependence of the $\mathrm{Cd}^{2+}$ and $\mathrm{Mn}^{2+}$ effects was explored further. The IspU transesterification rate increased with $\mathrm{Cd}^{2+}$ concentration up to $2 \mathrm{mM}$, whereas the reaction with the unmodified dinucleotide was unaffected over the concentration range examined (Fig. 4a). At concentrations of $\mathrm{CdCl}_{2}>0.5 \mathrm{mM}$, the actual rate of IspU cleavage exceeded that of IpU, an effect that was not achieved with any other metal ion. From $0-1 \mathrm{mM} \mathrm{Mn}^{2+}$, the IspU cleavage rate increased with little effect on the IpU reaction (data not shown). Above $1 \mathrm{mM}$, increasing $\mathrm{Mn}^{2+}$ concentration affected the reactions with IpU and IspU to the same extent, reflecting a general enhancement of ribozyme activity.

If the IspU-ribozyme-oligonucleotide complex formed a nonnative metal-ion site, exclusive enhancement of the IspU reaction might also be observed. To test this possibility, we investigated
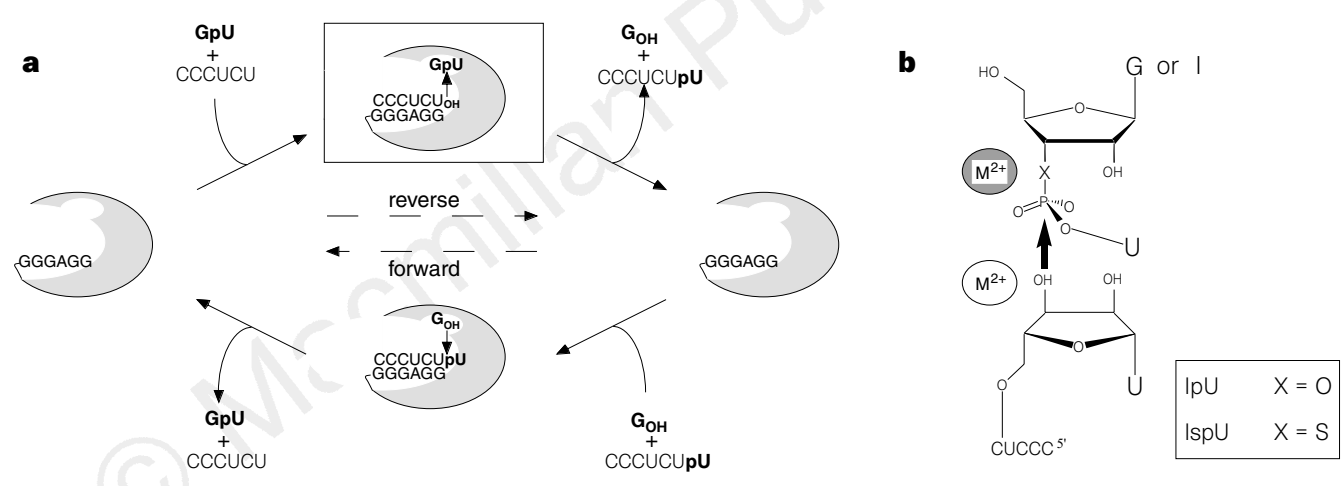

Figure 1 Ribozyme catalysis: reactions and proposed mechanism. a, Reactions catalysed by a truncated form of the Tetrahymena group I intron, the L-21 Scal ribozyme. The 'reverse' reaction models the second step of splicing, exon ligation. A dinucleotide, GpU, binds in the G-binding site, emulating the 3'-splice site, and an oligonucleotide (CCCUCU) added in trans functions as a $5^{\prime}$-exon mimic. Nucleophilic attack proceeds to liberate guanosine, the intact catalyst and the elongated oligonucleotide (CCCUCUpU), analogous to the ligated exons generated by self-splicing. The 'forward' reaction models 5 '-splice site cleavage. A guanosine molecule binds, and its $3^{\prime}$-hydroxyl acts as the nucleophile to cleave

the $3^{\prime}$-terminal nucleotide of an added oligonucleotide (CCCUCUpU), producing a dinucleotide (GpU) and a shortened 5'-exon analogue (CCCUCU). b, Model for RNA-catalysed phosphodiester bond cleavage. Detail of complex boxed in $\mathbf{a}$. The bold arrow indicates the trajectory of nucleophilic attack by the terminal $3^{\prime}$ hydroxyl of CCCUCU. The white ball represents the metal ion identified by Piccirilli et al. ${ }^{5}$ which interacts with the leaving group in the forward reaction; by microscopic reversibility, it interacts with the $3^{\prime}-O$ of the nucleophile in the reverse reaction shown here. The stippled ball is the metal ion that interacts with the leaving group in the cleavage of IpU and IspU, as tested here.

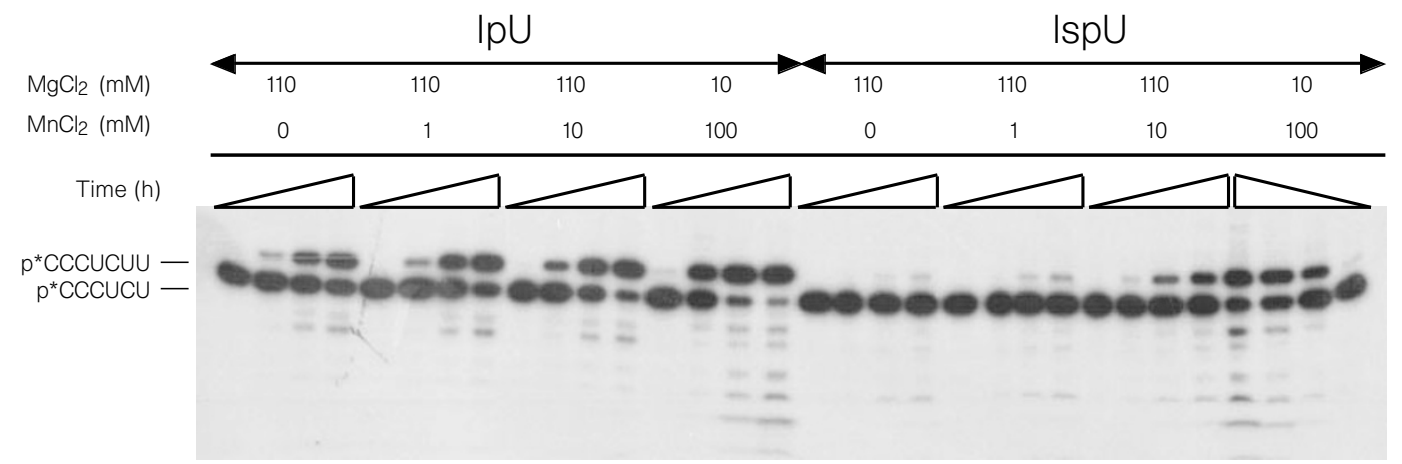

Figure 2 Cleavage of IspU requires $\mathrm{Mn}^{2+}$. Scanned autoradiograph of a polyacrylamide gel showing $\mathrm{IpU}$ and $\mathrm{IspU}$ reactions as a function of time. Timepoints shown are $0.05,2,12$ and $24 \mathrm{~h}$. The dinucleotide substrates ( $1 \mathrm{mM}$ ) were reacted with $100 \mathrm{nM} \mathrm{L-21}$ ribozyme, $1 \mu \mathrm{M}$ CCCUCU and a trace amount $(<1 \mathrm{nM})$ of $\mathrm{p}^{*} \mathrm{CCCUCU}$ at $\mathrm{pH} 7.0$ in the presence of $\mathrm{Mg}^{2+}$ and $\mathrm{Mn}^{2+}$ at the indicated concentrations. The small amount of product co-migrating with $\mathrm{p}^{*} \mathrm{CCCUCUpU}$ in the IspU lanes in the absence of $\mathrm{Mn}^{2+}$ was ribozyme-dependent and was also found in the absence of added dinucleotide ${ }^{27}$. The ribozyme was folded in $20 \mathrm{mM}$ $\mathrm{MgCl}_{2}$ and then added to the appropriate reaction mixture. 
whether $\mathrm{Cd}^{2+}$ was binding in a site capable of being occupied by $\mathrm{Mg}^{2+}$ by using $\mathrm{MgCl}_{2}$ as a competitor of the enhanced reaction (Fig. $4 \mathrm{~b})$. The IspU reaction was inhibited, whereas the IpU reaction was stimulated; this latter effect has been observed previously in studies of the reverse reaction using GpA as substrate ${ }^{13}$. Net inhibition by $\mathrm{Mg}^{2+}$ is seen in the ratio of the observed rates for IspU and IpU transesterification (diamonds in Fig. 4b), consistent with a common binding site for $\mathrm{Cd}^{2+}$ and $\mathrm{Mg}^{2+}$. The $\mathrm{Mn}^{2+}$-enhanced reaction was also inhibited by $\mathrm{Mg}^{2+}$ (data not shown), as previously shown for the forward reaction ${ }^{5}$. Apparently, the thio-substituted catalytic site still binds $\mathrm{Mg}^{2+}$, but the bound metal ion is not effective in catalysis.

The effect of metal ions in solution on reactions with sulphur leaving groups has been examined for intramolecular cleavage of nucleoside- $\left(3^{\prime} \rightarrow 5^{\prime}\right)-5^{\prime}$-thionucleotide substrates $\left(\mathrm{NpsN}^{\prime} \rightarrow\right.$ $\mathrm{N}>\mathrm{p}+\mathrm{s} \mathrm{N}^{\prime}$, where $\mathrm{N}$ is $\mathrm{C}$ or $\mathrm{U}$ and $\mathrm{N}^{\prime}$ is $\mathrm{A}$ or $\left.\mathrm{U}\right)$. It has been found that the rate of cleavage of $\mathrm{d}$ (ACGGTCT)rCpsd(ACGAGC) increases with 'softness' of the added metal ion ${ }^{19}$ or alternatively that cleavage of UpsU is unaffected by addition of either $\mathrm{Zn}^{2+}$ or $\mathrm{Cd}^{2+}$ relative to cleavage of unmodified phosphodiesters ${ }^{20}$. The preference for the catalytic metal ion in ribozyme-mediated IspU cleavage $\left(\mathrm{Cd}^{2+}>\mathrm{Mn}^{2+}>\mathrm{Zn}^{2+}>\mathrm{Co}^{2+}=\mathrm{Mg}^{2+}\right)$ stands in contrast to these results for uncatalysed cleavage, supporting the conclusion that a distinct site participates in catalysis.

Additionally, the metal-ion preference observed here for the reverse reaction differs from that determined for cleavage of $\mathrm{d}$ (CCCUCUspAAAAA) in the forward reaction $\left(\mathrm{Zn}^{2+}>\mathrm{Mn}^{2+}>\right.$ $\left.\mathrm{Cd}^{2+}>\mathrm{Co}^{2+}>\mathrm{Mg}^{2+}\right)^{5}$. This would be difficult to explain if the thio substrates were merely recruiting thiophilic metal ions from solu-
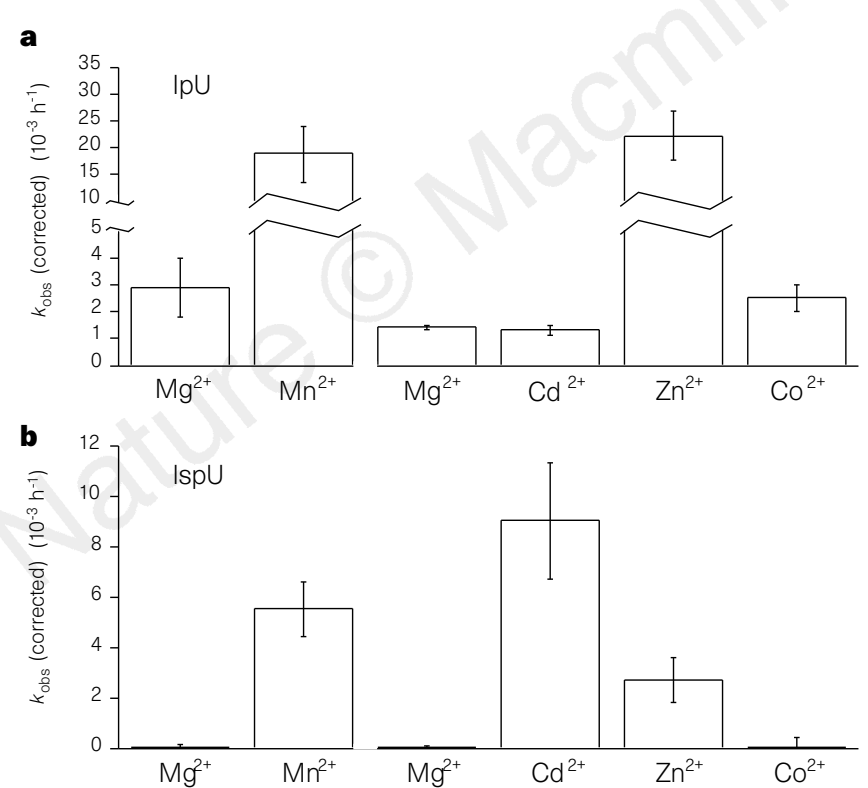

Figure 3 Metal specificity of reactions containing IpU and IspU. a, Reaction with the unmodified dinucleotide IpU was stimulated above the $\mathrm{Mg}^{2+}$-only rate by $\mathrm{Mn}^{2+}$ and by $\mathrm{Zn}^{2+}$. b, IspU reacted only in the presence of thiophilic metal ions. Reactions were carried out using $18 \mathrm{mM} \mathrm{MgCl}_{2}$ and $2 \mathrm{mM}$ of the indicated divalent metal chloride salt, apart from reactions with $\mathrm{MnCl}_{2}$ which contained $10 \mathrm{mM}$ $\mathrm{MgCl}_{2}$ and $10 \mathrm{mM} \mathrm{MnCl}_{2}$. First-order rate constants $\left(k_{\text {obs }}\right)$ were determined from initial rates (typically 4-8 timepoints) at $\mathrm{pH} 5.9$ and $40^{\circ} \mathrm{C}$ with $0.5 \mathrm{mM}$ dinucleotide, and represent an average of two $\left(\mathrm{MnCl}_{2}\right)$ or three (others) independent experiments. Values are corrected by subtracting the rate of formation of p*CCCUCUU in the absence of added dinucleotide. Reactions containing IpU, IspU and no added dinucleotide were done in parallel using the same stocks of folded ribozyme and metal ions. Errors shown are calculated standard errors. Two values are shown for $\mathrm{MgCl}_{2}$ : first bar, values determined in parallel with $\mathrm{MnCl}_{2}$ experiments; and third bar, values determined in parallel with $\mathrm{ZnCl}_{2}, \mathrm{CdCl}_{2}$ and $\mathrm{CoCl}_{2}$. tion, but it is what would be expected if the ribozyme were to provide two discrete binding sites for the two catalytic metal ions, each with its own ligand environment.

As shown here, the metal ion (stippled ion in Fig. 1b) stabilizing the leaving group during the reverse reaction would, by microscopic reversibility, be interacting with the nucleophile (3'-hydroxyl of $G$ or I) in the forward reaction. These two RNA enzyme reactions correspond to the exon ligation and 5'-splice-site cleavage steps of self-splicing, respectively. Conversely, the metal ion (white ion in Fig. 1b) stabilizing the leaving group in the forward reaction must be interacting with the nucleophile in the reverse reaction ${ }^{5}$. Kinetic evidence from metal-ion competition experiments also supports a model featuring two ions that are important for the chemical step ${ }^{21}$. Because the sulphur-substitution experiments were designed to look for metals in proximity to particular atoms, additional interactions (such as with the $2^{\prime}-O$ of G; ref. 22) may not have been detected. Two-metal-ion mechanisms have been explored as general solutions for how protein and RNA enzymes catalyse phosphoryl transfer ${ }^{7}$. The Tetrahymena group I ribozyme now provides the first example of an RNA enzyme that uses such a mechanism.

\section{Methods}

Polyacrylamide gel electrophoresis (PAGE). Oligonucleotides were separated on $20-24 \%$ polyacrylamide gels for both preparation (non-denaturing) and analysis (denaturing, $7 \mathrm{M}$ urea). Analytical gels were dried and then analysed using a Molecular Dynamics PhosphorImager.

RNA preparation: oligonucleotides and ribozyme. Ribo-oligonucleotides, CCCUCU and CCCUCUU, were synthesized, deprotected and purified using
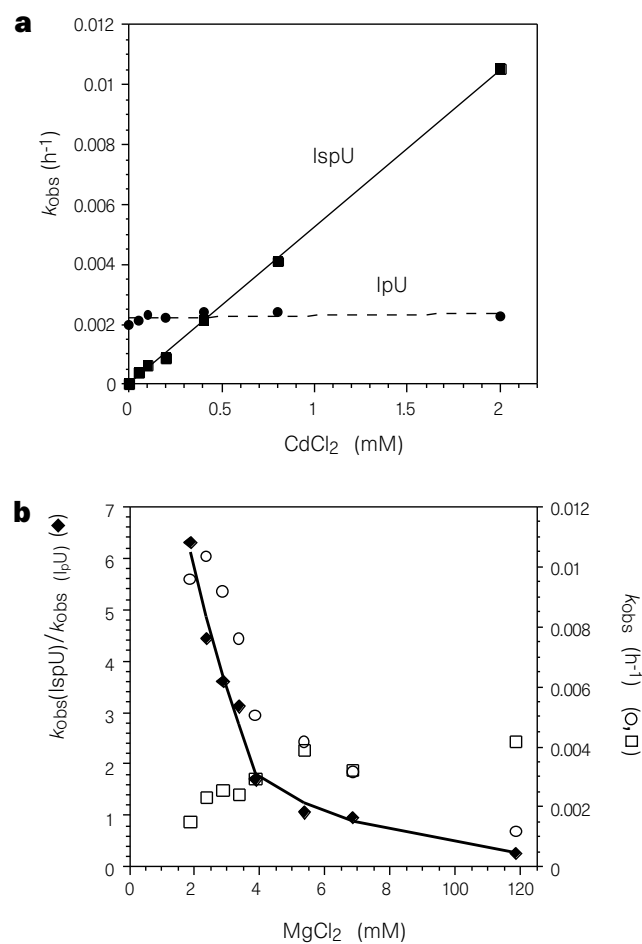

Figure $4 \mathrm{Cd}^{2+}$ interacts in the active site. a, $\mathrm{CdCl}_{2}(0-2 \mathrm{mM})$ accelerated the rate of transesterification of IspU; the rate for IpU was unaffected. At higher $\mathrm{CdCl}_{2}$ concentrations ( 4 and $8 \mathrm{mM}$ ), both $\mathrm{IpU}$ and IspU cleavage reactions were inhibited (data not shown). The line represents a linear fit (Kaleidagraph) to the data obtained at $\mathrm{pH} 5.9$ with $0.5 \mathrm{mM}$ dinucleotide. The total divalent-metal concentration was maintained at $20 \mathrm{mM}$ by adjustment of $\left[\mathrm{MgCl}_{2}\right] . \mathbf{b}, \mathrm{Mg}^{2+}$ competes for $\mathrm{Cd}^{2+}$ binding. Addition of $\mathrm{MgCl}_{2}(0-100 \mathrm{mM})$ to a reaction containing $18.5 \mathrm{mM}$ $\mathrm{MgCl}_{2}$ and $2 \mathrm{mM} \mathrm{CdCl}_{2}$ inhibited cleavage of the modified dinucleotide. Right axis, individual rate constants for cleavage of IspU (circles) and IpU (squares); left axis, ratio of these rate constants (diamonds). Reactions were buffered at $\mathrm{pH} 5.9$ and contained $0.5 \mathrm{mM}$ dinucleotide. 
standard procedures ${ }^{16}$. Oligonucleotides were $5^{\prime}$-end labelled with T4 polynucleotide kinase and $\left[\gamma^{-}{ }^{32} \mathrm{P}\right]$ ATP (for example, CCCUCU $\rightarrow \mathrm{p}^{*} \mathrm{CCCUCU}$; where $\mathrm{p}^{*}$ indicates the radioactive phosphorus). L-21 ScaI ribozyme was prepared by transcription from the ScaI-cut plasmid pT7L-21 and was purified as described ${ }^{23}$.

Dinucleotide preparation: IpU and IspU. Inosylyl- $\left(3^{\prime} \rightarrow 5^{\prime}\right)$-uridine (IpU) was purchased from Sigma and used without further purification. $3^{\prime}$-(Thioinosylyl)- $\left(3^{\prime} \rightarrow 5^{\prime}\right)$-uridine triethyl ammonium salt (IspU) was synthesized as described $^{6}$ with the following differences. The previously described $2^{\prime}, 3^{\prime}$ anhydroinosine $e^{24}$ was silylated using $t$-butyldiphenylsilyl chloride $(1.1 \mathrm{~mol}$ equiv) in dry pyridine (room temperature for $72 \mathrm{~h}$, then $60^{\circ} \mathrm{C}$ for $24 \mathrm{~h}$ ) to give $5^{\prime}$ - $O$ - $t$-butyldiphenylsilyl-2' $3^{\prime}$-anhydroinosine (75\%). (A $5^{\prime}$-silyl protecting group was also used in the synthesis of the $5^{\prime}-O$-dimethoxytrityl-2'-O-tbutyldimethylsilyl-3' $3^{\prime}$ thioinosine-3'-S-phosphoramidite used in ref. 25). Subsequent conversion to 9-[5'-O-( $t$-butyldiphenylsilyl)- $3^{\prime}$-deoxy- $3^{\prime}$-iodo$\beta$-D-xylofuranosyl]hypoxanthine was achieved in $70 \%$ yield by reaction with sodium iodide ( $4 \mathrm{~mol}$ equiv) and incremental addition of boron trifluorideetherate ( $3.5 \mathrm{~mol}$ equiv) over $48 \mathrm{~h}$ in dry acetonitrile at $0-4{ }^{\circ} \mathrm{C}$. Synthesis then progressed as described ${ }^{6}$, but using $5^{\prime}$ - $t$-butyldiphenylsilyl intermediates in place of the $5^{\prime}$-trityl-protected compounds. Silyl-protected IspU was deblocked by treatment with $\mathrm{NEt}_{3} \cdot \mathrm{HF}$ (triethylamine tris-hydrofluoride) and purified by chromatography on DEAE-Sephadex (elution with 0 to $0.5 \mathrm{M}$ triethylammonium bicarbonate), followed by flash chromatography on octadecylsilyl silica (elution with $2 \%$ methanol in water). The product was identical in every respect to the previously prepared sample.

Ribozyme reactions. The ribozyme was preincubated with $\mathrm{MgCl}_{2}$ in NaMES buffer ( $\mathrm{pH} 5.9$ or 7.0 ) for $20 \mathrm{~min}$ at $50^{\circ} \mathrm{C}$ (ref. 26). This ribozyme-metal mix was combined with the substrate oligonucleotide and incubated at $40^{\circ} \mathrm{C}$ for $5 \mathrm{~min}$. Reactions were initiated with the addition of the appropriate dinucleotide or an equal volume of $\mathrm{H}_{2} \mathrm{O}$ and incubated at $40^{\circ} \mathrm{C}$ for the duration of the experiment. Reactions were followed for $8-26 \mathrm{~h}$. A typical reaction included: $50 \mathrm{mM}$ NaMES, pH 5.9, 20-100 $\mathrm{mM} \mathrm{MgCl}_{2}, 100 \mathrm{nM} \mathrm{L-21} \mathrm{RNA,} \mathrm{trace}$ $\mathrm{p}^{*} \mathrm{CCCUCU}, 1 \mu \mathrm{M}$ CCCUCU and $0.5-1 \mathrm{mM}$ dinucleotide. In experiments where either the concentration of $\mathrm{MgCl}_{2}$ or the divalent ion was varied, the ribozyme was preincubated in $10-20 \mathrm{mM} \mathrm{MgCl}_{2}$ and then diluted into a reaction mixture containing the additional metal components and the substrate oligonucleotide. Divalent metal salts were $\geq 99.99 \%$ pure. $\mathrm{ZnCl}_{2}, \mathrm{CdCl}_{2}$ and $\mathrm{CoCl}_{2}$ were stored as $20 \mathrm{mM}$ stock solutions in $50 \mathrm{mM}$ NaMES, pH 5.9. Over the course of an experiment, reactions were sampled 4-8 times by removing aliquots of $1.5-2 \mu \mathrm{l}$ which were quenched by addition to 2.5 volumes of stop solution. The final concentration of EDTA in the stop solution was adjusted to ensure $>2$-fold excess of EDTA over the total divalent metal ion concentration.

Kinetics calculations. First-order rate constants $\left(k_{\mathrm{obs}}\right)$ were determined from initial rates. Values in Fig. 3 were corrected by subtracting the rate of product formation in the absence of added dinucleotide; rates in Fig. 4 were uncorrected. Previous work examining a metal-specificity switch ${ }^{5}$ summarized metal ion effects as "relief of the thio-effect", defined as a ratio of rate constants:

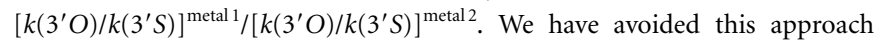
here because some of the $k\left(3^{\prime} S\right)$ values are close to zero and have large uncertainties: division then amplifies the uncertainty to an unacceptable level.

Received 23 April; accepted 13 June 1997.

1. Pyle, A. M. in Metal Ions in Biological Systems (eds Sigel, A. \& Sigel, H.) 479-520 (Dekker, New York 1996).

2. Cech, T. R. \& Herschlag, D. in Nucleic Acids and Molecular Biology (eds Eckstein, F. \& Lilley, D. M. J.) 1-17 (Springer, Berlin, 1996).

3. Grosshans, C. A. \& Cech, T. R. Metal ion requirements for sequence-specific endoribonuclease activity of the Tetrahymena ribozyme. Biochemistry 28, 6888-6894 (1989).

4. Celander, D. W. \& Cech, T. R. Visualizing the higher order folding of a catalytic RNA molecule. Science 251, 401-407 (1991)

5. Piccirilli, J. A., Vyle, J. S., Caruthers, M. H. \& Cech, T. R. Metal ion catalysis in the Tetrahymena ribozyme reaction. Nature 361, 85-88 (1993).

6. Weinstein, L. B., Earnshaw, D. J., Cosstick, R. \& Cech, T. R. Synthesis and characterization of an RNA dinucleotide containing a 3'-S-phosphorothiolate linkage. J. Am. Chem. Soc. 118, 10341-10350 (1996) Steitz, T. A. \& Steitz, J. A. A general two-metal-ion mechanism for catalytic RNA. Proc. Natl Acad. Sci. USA 90, 6498-6502 (1993).

8. Cech, T. R. et al. Mechanism and structure of a catalytic RNA molecule. Robert A. Welch Foundn Conf. Chem. Res. XXXVII, 91-110 (1993)

9. Inoue, T., Sullivan, F. X. \& Cech, T. R. New reactions of the ribosomal RNA precursor of Tetrahymena and the mechanism of self-splicing. J. Mol. Biol. 189, 143-165 (1986).

10. Michel, F., Hanna, M., Green, R., Bartel, D. P. \& Szostak, J. W. The guanosine binding site of the Tetrahymena ribozyme. Nature 342, 391-395 (1989).
11. Been, M. D. \& Perrotta, A. T. Group I intron self-splicing with adenosine: evidence for a single nucleoside-binding site. Science 252, 434-437 (1991).

12. Kay, P. S. \& Inoue, T. Catalysis of splicing-related reactions between dinucleotides by a ribozyme. Nature 327, 343-346 (1987).

13. McConnell, T. S. Involvement of guanosine and $\mathrm{Mg}^{2+}$ in the Tetrahymona ribozyme reaction. Thesis, Univ. Colorado (1994).

14. Bevilacqua, P. C., Sugimoto, N. \& Turner, D. H. A mechanistic framework for the second step of splicing catalyzed by the Tetrahymena ribozyme. Biochemistry 35, 648-658 (1996).

15. Bass, B. L. \& Cech, T. R. Specific interaction between the self-splicing RNA of Tetrahymena and its guanosine substrate: implications for biological catalysis by RNA. Nature 308, 820-826 (1984).

16. McConnell, T. S. \& Cech, T. R. A positive entropy change for guanosine binding and for the chemical step in the Tetrahymena ribozyme reaction. Biochemistry 34, 4056-4067 (1995).

17. Herschlag, D. \& Khosla, M. Comparison of $\mathrm{pH}$ dependencies of the Tetrahymena ribozyme reactions with RNA 2'-substituted and phosphorothioate substrates reveals a rate-limiting conformational step. Biochemistry 33, 5291-5297 (1994).

18. Pecoraro, V. L., Hermes, J. D. \& Cleland, W. W. Stability constants of $\mathrm{Mg}^{2+}$ and $\mathrm{Cd}^{2+}$ complexes of adenine nucleotides and thionucleotides and rate constants for formation and dissociation of MgATP and MgADP. Biochemistry 23, 5262-5271 (1984).

19. Kuimelis, R. G. \& McLaughlin, L. W. Cleavage properties of an oligonucleotide containing a bridged internucleotide 5'-phosphorothioate RNA linkage. Nucleic Acids Res. 23, 4753-4760 (1995).

20. Thomson, J. B., Patel, B. K., Jiménez, V., Eckart, K. \& Eckstein, F. Synthesis and properties of diuridine phosphate analogues containing thio and amino modifications. J. Org. Chem. 61, 6273-6281 (1996).

21. McConnell, T. S., Herschlag, D. \& Cech, T. R. Effects of divalent metal ions on individual steps of the Tetrahymena ribozyme reaction. Biochemistry 36, 8293-8303 (1997).

22. Sjögren, A.-S., Pettersson, E., Sjöberg, B.-M. \& Strömberg, R. Metal ion interaction with cosubstrate in self-splicing of group I introns. Nucleic Acids Res. 25, 648-653 (1997).

23. Zaug, A. J., Grosshans, C. A. \& Cech, T. R. Sequence-specific endoribonuclease activity of the Tetrahymena ribozyme: enhanced cleavage of certain oligonucleotide substrates that form mismatched ribozyme-substrate complexes. Biochemistry 27, 8924-8931 (1988).

24. Bhat, V., Stocker, E. \& Ugarkar, B. G. A new synthesis of 2', 3' -dideoxyinosine. Synth. Comm. 22, 14811486 (1992).

25. Sontheimer, E. J., Sun, S. \& Piccirilli, J. A. Metal ion catalysis during premessenger RNA splicing. Nature (this issue) EDS to update on page.

26. Herschlag, D. \& Cech, T. R. Catalysis of RNA cleavage by the Tetrahymena thermophila ribozyme. 1. Kinetic description of the reaction of an RNA substrate complementary to the active site. Biochemistry 29, 10159-10171 (1990).

27. Zaug, A. J. \& Cech, T. R. The intervening sequence RNA of Tetrahymena is an enzyme. Science 231, $470-475$ (1986).

Acknowledgements. We thank J. Piccirilli for initial inspiration and for advice on experimental design; A. Gooding and T. McConnell for materials; P. Bevilacqua and A. Szewczak for useful comments; and S. Sun and J. Piccirilli for sharing results before publication. This work was supported by a grant to T.R.C. from the NIH and a grant to R.C. from the BBSRC. T.R.C. is an investigator of the Howard Hughes Medical Institute and an American Cancer Society professor.

Correspondence and requests for materials should be addressed to T.R.C. (e-mail: thomas.cech@ colorado.edu).

\section{correction}

\section{$\mathrm{CO}_{2}$ fixation and \\ photoevolution of $\mathrm{H}_{2}$ and $\mathrm{O}_{2}$ in a mutant of Chlamydomonas lacking photosystem I}

\author{
E. Greenbaum, J. W. Lee, C. V. Tevault, S. L. Blankinship \\ \& L. J. Mets
}

Nature 376, 438-441 (1995)

We reported in this paper and elsewhere ${ }^{1}$ that mutants of the green alga Chlamydomonas reinhardtii that lacked detectable levels of functional photosystem I (PS I) are capable of photoreduction of atmospheric $\mathrm{CO}_{2}$, autotrophic growth, and sustained simultaneous photoevolution of $\mathrm{H}_{2}$ and $\mathrm{O}_{2}$. Although the absence of PS I in mutants $\mathrm{B} 4$ and $\mathrm{F} 8$ has been confirmed by physical, biochemical and genetic techniques, subsequent analyses in our own laboratories, as well as in those of colleagues to whom we have sent the mutants, indicate that there is variability in the PS I content of the cultures depending on growth conditions. Although some strains retain undetectable levels of P700, others contain variable $(0-20 \%)$ amounts of wild-type P700. (See also refs 2, 3).

\footnotetext{
1. Lee, J. W., Tevault, C. V., Owens, T. G. \& Greenbaum, E. Science 273, 364-367 (1996).

2. Olson, J. M., Owens, T. G., Lee, J. W., Tevault, C. V. \& Greenbaum, E. Science 275, 996 (1997).

3. Greenbaum, E., Lee, J. W., Tevault, C. V., Blankinship, S. L. \& Mets, L. J. Nature 379, 305(1996).
} 